\title{
Sinus node function in first three weeks after cardiac transplantation
}

\author{
A F MACKINTOSH, ${ }^{\star}$ D J CARMICHAEL, C WREN, R CORY-PEARCE, $†$ T A H ENGLISH \\ From Papworth Hospital, Cambridge
}

SUMMARY Donor sinus node function was studied in 10 patients from day 4 to day 24 after cardiac transplantation. Cycle length, atrial arrhythmias, corrected sinus node recovery time, and estimated sinoatrial conduction time were recorded daily. Five patients had at least two sets of results suggesting sinus node dysfunction (group A) while five patients had no such abnormalities (group B). The prognosis in group A was poor, with four of the five patients dying within four months of the operation; one unexpected death from arrhythmias was recorded by ambulatory electrocardiographic monitoring. All five patients in group B survived for at least eight months. In nine patients sinus node function varied from day to day, with corrected sinus node recovery time reaching a peak at 11 to 18 days after operation. The longest corrected sinus node recovery time was $11160 \mathrm{~ms}$. Neither the differences between the patients, nor the day to day variation, could be explained solely by the degree of rejection as assessed by biopsy or by the ischaemia time of the heart during procurement. Sinus node dysfunction soon after transplantation is associated with a poorer prognosis and might be the terminal event in some cases.

After cardiac transplantation the new heart remains isolated from the autonomic nervous system. ${ }^{12}$ Several studies have explored the function of the human sinus node in this unusual state. ${ }^{2-6}$ These investigations have all been on patients who have survived at least a year after the operation and have no evidence of rejection in a simultaneous myocardial biopsy. Thus sinus node function has been studied only in a selected group of patients who have survived for some time after the operation.

The first five patients to receive a heart transplant at Papworth Hospital, Cambridge, had an unexpectedly high incidence of sinoatrial arrhythmias in the immediate postoperative period. We therefore undertook a prospective study of sinus node function during the first three and a half weeks after transplantation. The first aim was to explore the effects of the operation on the human sinus node. The second was to assess whether sinus node function would provide a guide to the immunological state of the rest of the heart.

^Present address: St James's University Hospital, Leeds. †British Heart Foundation senior research fellow.

Accepted for publication 20 August 1982

\section{Patients and methods}

Eleven consecutive patients undergoing cardiac transplantation were studied. One patient developed fits and unconsciousness one week after the operation, which prevented further testing. The rest of this report is concerned with the remaining 10 patients. They were all men, aged from 22 to 52 years (mean 40).

The donor hearts were all brought to Papworth from other hospitals. Immediately before removal from the donor they were perfused with a cardioplegic solution at $4 \mathrm{C}$ containing procaine and a high concentration of potassium and magnesium (Table 1). The hearts were transported at about $4 \mathrm{C}$, eight in cardioplegic solution and two in Ringer's solution. The ischaemia times of

Table 1 Papworth Hospital cardioplegic solution

\begin{tabular}{llc}
\hline & Ions & mmol/l \\
\hline & $\mathrm{Mg}$ & 16 \\
$\mathrm{Na}$ & 149 \\
$\mathrm{~K}$ & 20 \\
$\mathrm{Ca}$ & 2 \\
& $\mathrm{Cl}$ & 172 \\
& $\mathrm{HCO}$ & 10 \\
& Procaine & $1 \cdot 2$ \\
$\mathrm{pH} 7 \cdot 4$ & & \\
Osmolarity 340 mOsmol/kg $\mathrm{H}_{2} \mathrm{O}$ & \\
\hline
\end{tabular}


Table 2 Drug treatment during study period

(1) Prednisolone $1 \mathrm{mg} / \mathrm{kg}$ per d

(2) Azathioprine $1.5-2.5 \mathrm{mg} / \mathrm{kg}$ per d

(3) Antihuman thymocyte globulin (ATG) $250-1000 \mathrm{mg} / \mathrm{d}$

(4) Cimetidine $1 \mathrm{~g} / \mathrm{d}$

(5) Hydrochlorothiazide $25-50 \mathrm{mg} / \mathrm{d}$

(6) Triamterene $50-100 \mathrm{mg} / \mathrm{d}$

(7) Amphotericin throat lozenges

the donor hearts ranged from 113 to 190 minutes (mean 158). The hearts were inserted by the techniques developed at Stanford University Medical Centre. ${ }^{7}$ The donor right atrium is sutured to the posterior and lateral walls of the recipient right atrium so that blood can drain from the recipient's vena cavae into the donor right atrium. The donor sinus node is protected by ligating and dividing the donor superior vena cava 1.5 $\mathrm{cm}$ above the cavoatrial junction. At the end of each operation two epicardial wires are applied to the donor right atrium.

Sinus node function was assessed daily from postoperative days 4 to 24 . This period was chosen because some of the patients received isoprenaline infusions during the first three days and the atrial wires were removed soon after the 24th day. The routine postoperative care at Papworth Hospital has been described previously. ${ }^{8}$ The drug treatment during the study period is shown in Table 2. No digoxin or other antiarrhythmic drugs were given to these patients.

The tests of sinus node function were selected so that they could be performed easily with simple, sterilisable, equipment in the intensive care area. Testing was carried out in the middle of the morning after 10 minutes bed rest. The temporary epicardial wires were used for bipolar atrial pacing, with measurements being taken from the external $P$ waves. The stimulus strength was twice the threshold value, with a pulse width of $1 \mathrm{~ms}$. The spontaneous cycle length of the donor atrium was recorded. This varied little in the denervated heart with the patient at rest. The sinus node recovery time was found by pacing for one minute at $100,110,120$, and 130 beats per minute or 110,120 , 130 , and 140 beats per minute if the spontaneous rate was above 100 per minute. On each occasion the spontaneous cycle length was subtracted from the recovery time to give the corrected sinus node recovery time. The estimated sinoatrial conduction time was calculated by a method similar to that described by Narula and colleagues. ${ }^{9}$ For this the atrium was paced for nine cycles at a rate 10 beats per minute faster than the spontaneous rate. The sinoatrial conduction time, that is the estimated conduction time into and out of the node, is the duration of the first post-pacing cycle minus the duration of the last spontaneous cycle before the onset of pacing. The spontaneous cycle varied little, so a single measurement was used rather than the mean of a number of cycles. On each occasion the sinoatrial conduction time was measured five times and the mean value calculated.

A normal range for these sinus node tests cannot be applied to denervated hearts soon after operation. But in other patients in our hospital the normal upper limit of the corrected sinus node recovery time is $525 \mathrm{~ms}$ and the sinoatrial conduction time is $250 \mathrm{~ms}$. The cycle length of a transplanted heart one year or more after operation is normally less than $800 \mathrm{~ms} .^{16}$

\section{Results}

The 10 patients showed a wide range of results and could be divided into two groups on the basis of the maximum values recorded during the study period (Table 3). The five patients in group A had pacing results outside our normal values for innervated hearts, atrial tachycardias, or a maximum cycle length above $1000 \mathrm{~ms}$. All patients in this group had at least two of these features. The recovery time could be grossly abnormal. Fig. 1 shows a 12 second pause on cessation of pacing in case 2 . In contrast, the other five patients (group B) all had corrected recovery times below 525 $\mathrm{ms}$, sinoatrial conduction times below $250 \mathrm{~ms}$, and

Table 3 Sinus node function tests in the 10 patients

\begin{tabular}{|c|c|c|c|c|c|c|c|}
\hline & $\operatorname{Max} C L(m s)$ & $\underset{(m s)}{\operatorname{Max} C S N R T}$ & $\begin{array}{l}\text { Postop day for } \\
\max C S N R T\end{array}$ & $\underset{(m s)}{\operatorname{Max} S A C T}$ & $\begin{array}{l}\text { Postop day for } \\
\max S A C T\end{array}$ & $\begin{array}{l}\text { Atrial tachycardia } \\
\text { during study period }\end{array}$ & Outcome \\
\hline \multicolumn{8}{|l|}{ Group A } \\
\hline Case 1 & 1020 & 835 & 12 & 279 & 12 & - & Alive at 27 months \\
\hline Case 2 & 1240 & 11160 & 12 & 248 & 5 & - & Died at 10 weeks \\
\hline Case 3 & 890 & 615 & 15 & 350 & 10 & - & Died at 18 weeks \\
\hline Case 4 & 1005 & 1020 & 18 & 145 & 18 & + & Died at 8 weeks \\
\hline Case 5 & 1100 & 1240 & 13 & 313 & 18 & + & Died at 7 weeks \\
\hline \multicolumn{8}{|l|}{ Group B } \\
\hline Case 6 & 780 & 230 & 14 & 130 & 9 & - & Alive at 23 months \\
\hline Case 7 & 890 & 450 & 16 & 173 & 16 & - & Alive at 21 months \\
\hline Case 8 & 920 & 430 & 17 & 140 & 14 & - & Alive at 20 months \\
\hline Case 9 & 770 & 390 & 11 & 145 & 11 & - & Died at 9 months \\
\hline Case 10 & 670 & 165 & a & 125 & a & - & Alive at 15 months \\
\hline
\end{tabular}

Max CL, maximum cycle length; max CSNRT, maximum corrected sinus node recovery time; max SACT, maximum estimated sinoatrial conduction time; $a$, no day to day variation. 


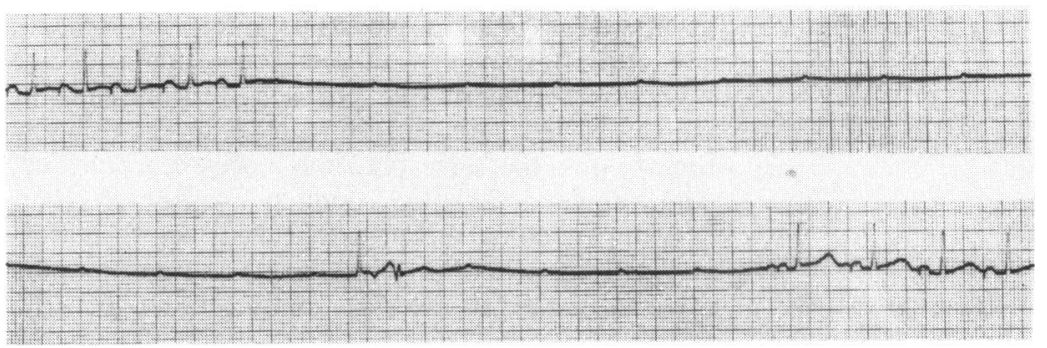

Fig. 1 Continuous recording of lead $2(25 \mathrm{~mm} / \mathrm{s})$ in case 2 showing 12 seconds of asystole after cessation of pacing. Atrial pacing is switched on again at the end of the trace. The activity of the recipient atrial remnant can be seen during the period of asystole of the donor atria and ventricles.

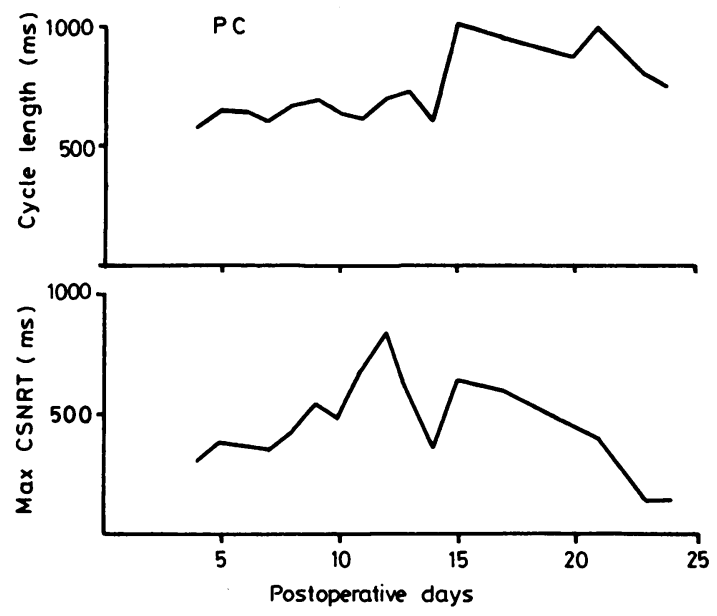

Fig. 2 Cycle length and maximum corrected sinus node recovery time on each day in case 1.
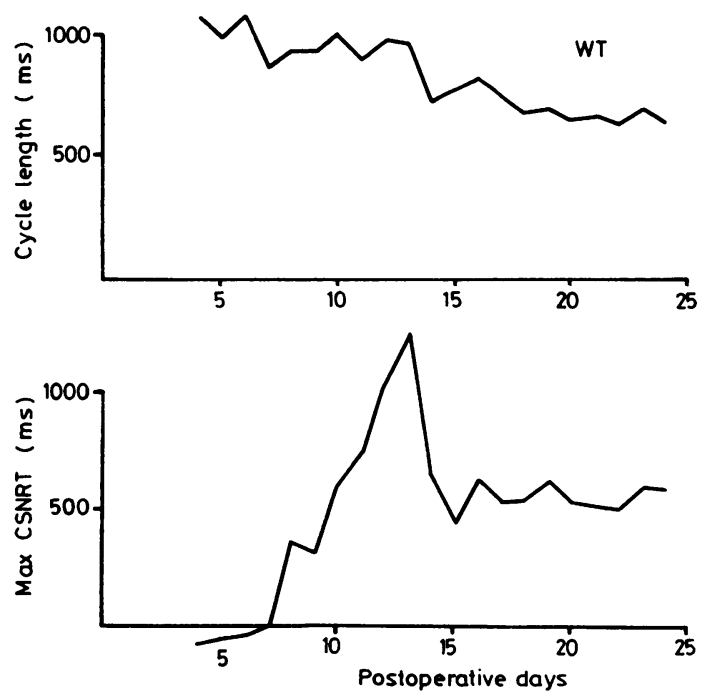

Fig. 3 Cycle length and maximum corrected sinus node recovery time on each day in case 5. cycle lengths below $1000 \mathrm{~ms}$ on each day. No atrial arrhythmias were seen in this second group during the study period.

In nine of the 10 patients considerable day to day variation occurred in the tests. The corrected recovery time lengthened progressively up to a maximum at 11 to 18 days followed by a shortening (Table 3, Fig. 2 and $3)$. The conduction time in these patients also reached a peak at 5 to 18 days and then fell.

The cause of the difference in results between the two groups and the day to day variability was not clear. The changes did not correlate with the degree of rejection as assessed by endocardial biopsy. For example, biopsies on days 10 and 23 from the patient whose results are illustrated in Fig. 2 were normal. Biopsies from the patient illustrated in Fig. 3 showed no rejection on days 11,21 , and 31 . In contrast, case 9 had severe rejection on day 8 but the sinus node function testing was unremarkable throughout. Nor were conduction abnormalities related to a longer ischaemia time of the donor heart at the time of transplantation. The mean time in group A was 146 minutes and in group B it was 169 minutes. Day to day variations in plasma sodium or potassium concentrations had no noticeable influence on sinus node function.

The subsequent progress of the patients in group A was poor. Three of the five patients died during episodes of rejection at seven, eight, and 10 weeks after operation. One of these deaths was an unexpected cardiac arrest at another hospital while undergoing preliminary assessment for suspected rejection. Another patient in this group (case 3) died unexpectedly during electrocardiographic monitoring at our hospital. The remaining patient is well two years after the operation and has had no demonstrated arrhythmias.

In contrast to these poor results the five patients in group B all survived eight months and four are alive 15 to 23 months after the operation, though case 6 was paced prophylactically at five months after asymptomatic atrial pauses had been seen on ambulatory monitoring. He also had one paroxysm of atrial flutter during an episode of rejection. No arrhythmias have 


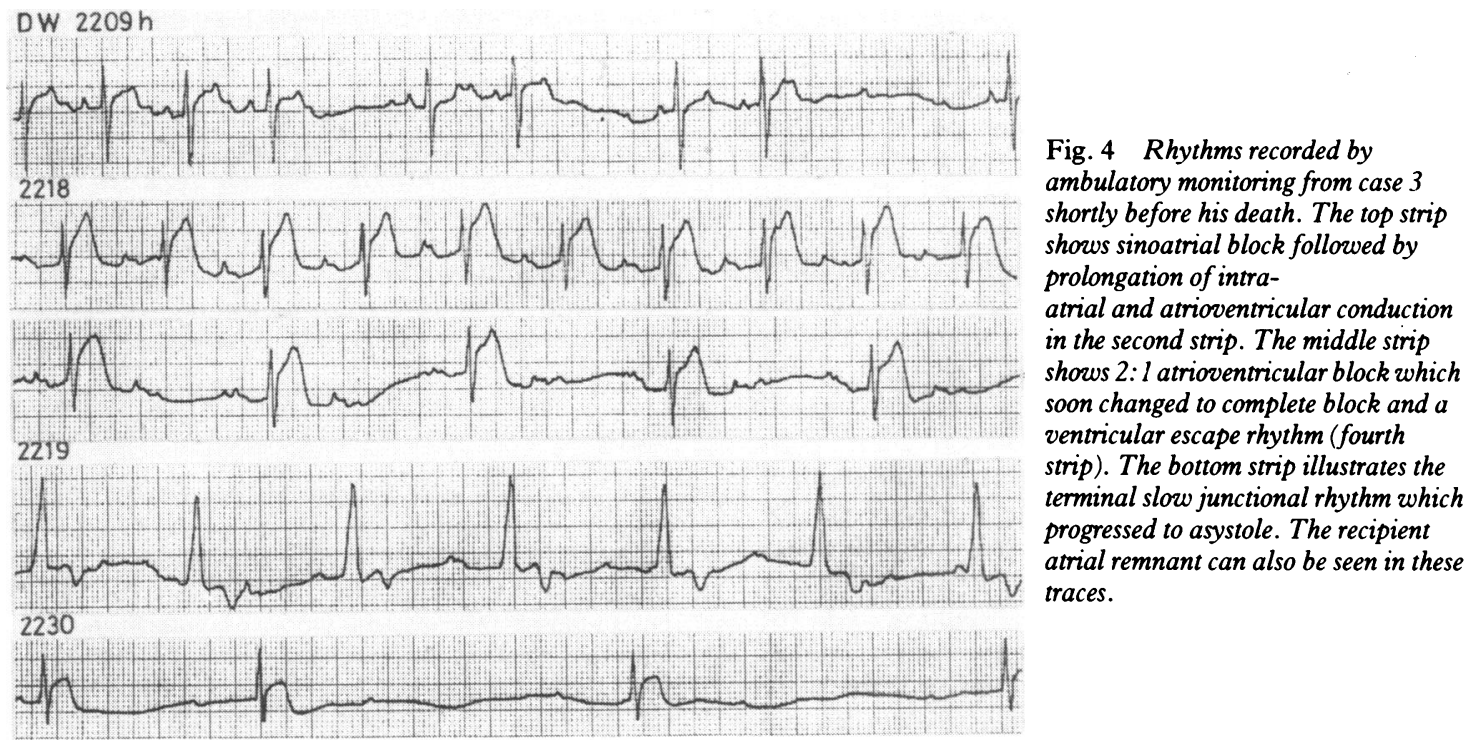

been seen in the other four patients in spite of at least two 24 hour periods of ambulatory electrocardiographic monitoring. Case 9 died from acute rejection at nine months.

Case 3, who died during ambulatory monitoring, had been shown to have asymptomatic atrial pauses six weeks before his death. At that time they were not thought to be important. When he was admitted for a routine endocardial biopsy four months after the operation, the opportunity was taken to perform a further 24 hour tape. At this time he was well and had already returned to part-time work. He was found dead in bed early the next morning with the recorder still running. The tape showed that about 20 minutes after he went to bed he began to develop periods of sinoatrial block (Fig. 4). A few minutes later prolongation of both intra-atrial and atrioventricular conduction was seen. Second degree atrioventricular block soon followed. A minute later he was in complete atrioventricular block with an escape rhythm probably of ventricular origin. This reverted to a junctional rhythm which became slower and slower until asystole occurred 10 minutes later. Necropsy examination showed a moderate degree of rejection.

\section{Discussion}

This study has shown a high incidence of sinus node dysfunction in the first few weeks after cardiac transplantation. The abnormalities described seem to be associated with a poor prognosis as only one of the five patients affected survived more than four months after the operation. The low incidence of sinus node disorders reported in earlier studies may have resulted from investigating patients a year or more after operation; the patients with abnormalities may not have survived for this length of time. Another possibility is that the dysfunction is temporary. This study was not designed to test these theories.

The cause of this sinus node dysfunction remains uncertain. One possibility is surgical trauma to the node or its blood supply. All operations were done by the same surgeon and care was taken to prevent any trauma to the donor heart in the region of the superior vena cava/right atrial junction. Surgical techniques were identical in the two groups, as were the drugs used.

Another explanation could be that the sinus node was abnormal before removal from the donor. The electrocardiograms taken at this time show no evidence of sinus node dysfunction. The period of ischaemia while the heart is transported and inserted into the patient could be the cause of the nodal disorders. Damage to the heart occurs during this period but it is reversible. ${ }^{10}$ The sinus node may be more resistant to the protective effects of cold cardioplegic solution than the rest of the heart. ${ }^{11}$ But longer ischaemia times were not associated with sinus node dysfunction. The mean ischaemia time in those patients without abnormalities (group B) was slightly greater than in those with dysfunction (group A). The differences in sinus node function, however, could be produced by more subtle variations in the preservation technique.

Other reports have implicated acute rejection as the main cause of atrial arrhythmias in both dogs ${ }^{12} 13$ and humans ${ }^{14-16}$ after transplantation. In this study rejection as assessed by biopsy did not discriminate between patients who developed abnormalities and 
those who did not. In addition, the degree of rejection did not explain individual day to day variations in the tests. On the other hand, an immunological mechanism might have a maximum effect about two weeks after the operation and the nine patients with considerable variation all had a maximum corrected sinus node recovery time between 11 and 18 days after transplantation. Immunological events undetected by biopsy could be important. But such a mechanism could not be the sole cause of the dysfunction as abnormalities could often be detected right at the beginning of the study period on day 4 ; rejection would take longer to develop.

The sinus node dysfunction is probably the result of a combination of factors. The initial event could be ischaemia at the time of transplantation. Subtle forms of rejection might then limit healing or produce further damage. This type of explanation would account for the poorer prognosis in these patients. Animal studies and detailed electrophysiological investigations of long-term survivors are being undertaken to try and elucidate the problem.

Whatever the cause of the sinus node dysfunction, the death of one patient during ambulatory monitoring illustrates that pacemaker tissue disorders are important after cardiac transplantation. In the general population sinus node dysfunction is a common cause of symptoms but is rarely fatal. ${ }^{17-19}$ The subsidiary pacemakers in the innervated heart will provide some form of escape rhythm. Such rhythms seem less reliable in these denervated hearts. Recognised causes of death after cardiac transplantation do not include cardiac arrhythmias. ${ }^{20}$ But arrhythmias cannot be diagnosed at necropsy. The terminal event in some cases could be severe sinus node dysfunction.

\section{References}

1 Stinson EB, Griepp RB, Schroeder JS, Dong E Jr, Shumway NE. Hemodynamic observations one and two years after cardiac transplantation in man. Circulation 1972; 45: 1183-94.

2 Cannom, DS, Graham AF, Harrison DC. Electrophysiological studies in the denervated transplanted human heart: response to atrial pacing and atropine. Circ Res 1973; 32: 268-78.

3 Cannom DS, Rider AK, Stinson EB, Harrison DC. Electrophysiologic studies in the denervated transplanted human heart. II Response to norepinephrine, isoproterenol and propranolol. Am $\mathcal{F}$ Cardiol 1975; 36: 859-66.

4 Goodman DJ, Rossen RM, Ingham R, Rider AK,
Harrison DC. Sinus node function in the denervated human heart. Effect of digitalis. Br Heart $\mathcal{f}$ 1975; 37: 612-8.

5 Harrison DC, Mason JW, Schroeder JS, Stinson EB. Effects of cardiac denervation on cardiac arrhythmias and electrophysiology. Br Heart f 1978; 40, suppl: 17-23.

6 Mason JW. Overdrive suppression in the transplanted heart: effect of the autonomic nervous system on human sinus node recovery. Circulation 1980; 62: 688-96.

7 Stinson EB, Dong E, Iben AB, Shumway NE. Cardiac transplantation in man. III Surgical aspects. Am $\mathcal{F}$ Surg 1969; 118: 182-7.

8 English TAH, Cooper DKC, Cory-Pearce R. Recent experience with heart transplantation. Br Med $\mathcal{F}$ 1980; 281: 699-702.

9 Narula OS, Shantha N, Vasquez M, Towne WD, Linhart JW. A new method for measurement of sinoatrial conduction time. Circulation 1978: 58: 706-14.

10 Billingham ME, Baumgartner WA, Watson DC, et al. Distant heart procurement for human transplantation. Ultrastructural studies. Circulation 1980; 62, suppl: 1119.

11 Gliklich J, Chan F, Hoffman B. Electrophysiology of the canine sinus node during cardiopulmonary bypass: technique for localization and response to cold cardioplegia (abstract). Am f Cardiol 1981; 47: 405.

12 Lower RR, Dong E Jr, Glazener FS. Electrocardiograms of dogs with heart homografts. Circulation 1966; 33: 45560.

13 Bieber CP, Stinson EB, Shumway NE. Pathology of the conduction system in cardiac rejection. Circulation 1969; 39: 567-75.

14 Berke DK, Graham AF, Schroeder JS, Harrison DC. Arrhythmias in the denervated transplanted human heart. Circulation 1973; 47 \& 48, suppl 3: 112-5.

15 Schroeder JS, Berke DK, Graham AF, Rider AK, Harrison DC. Arrhythmias after cardiac transplantation. Am f Cardiol 1974; 33: 604-7.

16 Mason JW, Stinson EB, Harrison DC. Autonomic nervous system and arrhythmias: studies in the transplanted denervated heart. Cardiology 1976; 61: 7587.

17 Rokseth R, Hatle L. Prospective study on the occurrence and management of chronic sinoatrial disease, with follow-up. Br Heart $\mathcal{F}$ 1974; 36: 582-7.

18 Hatle L, Bathen J, Rokseth R. Sinoatrial disease in acute myocardial infarction. Long-term prognosis. $\mathrm{Br}$ Heart $\mathcal{f}$ 1976; 38: 410-4.

19 Lien WP, Lee YS, Chang FZ, Lee SY, Chen CM, Tsai N HC. The sick sinus syndrome. Natural history of N dysfunction of the sinoatrial node. Chest 1977; 72: 628-34.

20 Schroeder JS. Current status of cardiac transplantation, 1978. FAMA 1979; 241; 2069-71.

Requests for reprints to Dr A F Mackintosh, Cardiac Department, St James's University Hospital, Leeds $\stackrel{\leftrightarrow}{?}$ LS9 7TF. 